Georgia State University ScholarWorks@ Georgia State University

2013

\title{
Challenging the Canon: LGBT Content in Arts Education Journals
}

Patrick K. Freer

Georgia State University, pfreer@gsu.edu

Follow this and additional works at: https://scholarworks.gsu.edu/music_facpub

Part of the Music Commons

\section{Recommended Citation}

Freer, P. K. (2013). Challenging the Canon: LGBT Content in Arts Education Journals. Bulletin of the Council for Research in Music Education, (196). 45. http://dx.doi.org/10.5406/bulcouresmusedu.196.0045.

This Article is brought to you for free and open access by the School of Music at ScholarWorks @ Georgia State University. It has been accepted for inclusion in Music Faculty Publications by an authorized administrator of ScholarWorks @ Georgia State University. For more information, please contact scholarworks@gsu.edu. 


\title{
Challenging the Canon: LGBT Content in Arts Education Journals
}

\author{
Patrick K. Freer \\ Georgia State University \\ Atlanta, GA
}

\begin{abstract}
A B STRACT
The purpose of this study was to examine LGBT-related content across arts education journals in order to identify prevalence, themes, and trends. This study consisted of a content analysis of peer-reviewed articles appearing in the major journals affiliated with professional arts education associations in the United States. A total of 4,193 articles were published from 2000 to 2012 in the 11 journals, of which 70 (1.67\%) included LGBT-related content. The percentage of $L G B T$-related content was steady over time. The most frequent LGBT themes in discipline-specific journal content related to pedagogy, the contributions of LGBT persons to art forms, gender, social justice, and homophobia. A more focused analysis included two pairs of long-running journals purposed for similar audiences and considered all article content since the journals' inception: Music Educators Journal (1914) and Art Education (1948); and the Journal of Research in Music Education (1953) and Studies in Art Education (1959). The emergence of LGBTrelated content, including letters to the editor, followed similar paths in the two practitioneroriented journals. Music education articles referencing LGBT topics appeared later and are less numerous than in other arts disciplines. Analysis suggests methodological issues to be addressed in future research studies and points toward strategies for introducing LGBT-related content where none has yet been published.
\end{abstract}

\section{CHALLENGING THE CANON: LGBT CONTENT IN ARTS EDUCATION JOURNALS}

Four articles associated with LGBT (lesbian, gay, bisexual, and transgender) topics have appeared in the Music Educators Journal since the first overt mention of sexual orientation was published in the journal's pages (Bergonzi, 2009). Since that time, national symposiums in 2010 and 2012 explored intersections between "LGBT Studies and Music Education." This is an opportune moment to examine LGBT-related content in our professional journals in order to establish a basis for historical scholarship and future research efforts.

There is no published analysis of LGBT-related journal content in fields specific to teacher education or the arts. Researchers have conducted such analyses of academic journal content in other domains, with most situated in counseling, sociology, and psychology. Titles given to several of these studies include images of illumination 
as metaphorical descriptions for the emergence of LGBT-related content in professional journals. Phrases in these titles include "shedding light on thirteen years of darkness" (Blumer, Green, Knowles, \& Williams, 2012), and "twenty years and still in the dark?" (Clark \& Serovich, 1997). Other titles indicate a paucity of LGBTrelated content in both journals and education textbooks, including expressions such as "eight articles, eight journals, eight years" (Phillips, 2010) and "among the missing" (Van Voorhees \& Wagner, 2002). Several articles have contained analyses of LGBTrelated issues in teacher education primers, with one title describing a "gay ghetto in the geography of education textbooks" (Jennings \& Macgillivray, 2011; Young \& Middleton, 2002).

The Journal of Counseling Psychology has published two foundational analyses of LGBT-related journal content as evidenced by citations of these studies in every subsequent related review. The first was an analysis of both content and method in research articles pertaining to lesbians and gays in six major counseling journals from 1978 to 1989 (Buhrke, Ben-Ezra, Hurley, \& Ruprechet, 1992). Of the 6,661 studies reviewed in that analysis, $43(0.65 \%)$ focused on variables related to lesbian or gay sexual orientation. The researchers noted a lack of empirical studies and concluded with a series of recommendations for conducting research on issues concerning lesbian women and gay men. These included the development of empirical studies, the clear and accurate presentation of limits to generalization, the inclusion of diverse populations, the grounding of research in theory, and the publication of research related to lesbians and gays in mainstream academic journals. A decade later, the authors of the second foundational article largely replicated the analysis of Buhrke et al. (1992), though expanding the number of counseling journals to eight, examining the years from 1990 to 1999 , and paying particular focus to content related to bisexuality (Phillips, Ingram, Smith, \& Mindes, 2003). A total of 5,628 articles were reviewed for this second study, of which 119 (2.11\%) were identified as related to LGBT issues and 64 (53.78\%) reported results of empirical studies. Relative to the earlier suggestions of Burkhe et al. (1992), the authors noted enhancements in the percentage of empirical articles and the development of theoretical contexts but indicated continuing areas for improvement with regard to generalization, gender parity, and the overall diversity of study populations. The authors also observed an increase in the number and quality of articles related to practice.

The purpose of the present investigation was to determine the status of LGBTrelated article content in arts education through identification of prevalence, themes, and trends. Three questions guided this study of arts education journals: when was the earliest appearance and what is the prevalence of LGBT-related content; what are the characteristics of LGBT-related articles; and what similarities and/or differences can be seen in the emergence of LGBT-related content in pairs of similarly-purposed journals? 


\section{METHOD}

This study consisted of a content analysis of peer-reviewed articles appearing in the major journals published by professional arts education associations in the United States. Included in the analysis were articles published in 11 journals affiliated with the National Association for Music Education (General Music Today, Journal of Music Teacher Education, Journal of Research in Music Education, the Music Educators Journal, Update: Applications of Research in Music Education), the National Art Education Association (Art Education, Studies in Art Education), the National Dance Association (Journal of Physical Education, Recreation \& Dance), the National Dance Education Organization (Journal of Dance Education), the American Alliance for Theatre Education (Youth Theatre Journal), and one journal collectively supported by many of these organizations, Arts Education Policy Review.

The review proceeded in three phases. The task of the first phase was to identify the earliest mention of LGBT-related content published in each journal. This examination sought to review all content, regardless of article type or peer-reviewed status. The focus of the second phase was peer-reviewed and editorial content published in these journals during the 13-year period from 2000 to 2012. Full-length articles, research reports, essays, extended abstracts, and editorial commentaries were included because they were likely to be peer-reviewed. "In the Classroom," "About the Law," "Technology Today," and similar types of columns were included if they referenced a specific author and reflected an academic writing style. Book and media reviews, letters to the editor, reports, announcements, recurring columns by an association's elected officials, memorial columns, and minutes of meetings were excluded because they often are not peer-reviewed.

The third phase of the review included a more focused examination of all LGBTrelated content since inception in Art Education, Journal of Research in Music Education, the Music Educators Journal, and Studies in Art Education. The same criteria were employed for this review, except that letters to the editor were included as they provided insights concerning social/historical context and reader reaction.

The process of identifying LGBT-related article content began with procedures developed for a similar review of counseling journals (Phillips et al., 2003). The author examined all article titles and abstracts (when available) in the selected journals during the specified time periods. When a title or abstract indicated content consistent with LGBT-related issues, the author conducted a line-by-line examination of the article for verification purposes. To locate LGBT-related content that might not be indicated by the title and/or abstract, keyword searches were conducted using the search functions embedded within each journal's online homepage and multiple databases as appropriate to the journal (e.g. JSTOR, EBSCOhost, and ProQuest). Keywords included, both individually and in combination: gay, lesbian, homosexual, bisexual, transgender, sexual (as in LGBT-related sexual orientation), and queer. Published content was included in the study if LGBT-related issues were the main topic, were featured prominently, or 
were mentioned repeatedly through the article. Published content was not included in the study when LGBT-related issues or terms were mentioned in passing (e.g., in a list without further description or focus), or when the same terms were used with alternate meanings not related to the study (e.g., where "gay" meant "happy").

A coding form was developed for the present study, partially modeled after previous content analyses of LGBT-related journal content (see Huang et al., 2010). Articles deemed to contain LGBT-related content were coded by type: empirical (including all methodological types), practical, positional (including commentaries, philosophical and theoretical pieces), or historical. Each of these articles was analyzed via line-byline examination and assigned between one and three content descriptors. The list of descriptors began with the 41 categories identified in a similar review of LGBT content in counseling journals (Phillips et al., 2003). Several items were renamed to appropriately fit the educational context of this review (i.e., "training" was renamed as "teacher education" and "counseling techniques" was renamed as "pedagogy"), with others renamed to reflect current terminology (i.e., "civil liberty issues" was renamed as "social justice"). Descriptors specific to counseling were removed; descriptors specific to arts education were added, including "critique of artworks," "definitions of culture," and "LGBT contributions to art form."

To address issues of validity and reliability, two graduate students at the researcher's home institution randomly selected $10 \%$ of the total pool of articles with a goal of identifying those with LGBT-related content and comparing the results with those of the researcher. The Kappa value (where values between .61 and .80 indicate substantial agreement) for interrater reliability at this stage was $\kappa=.86$. The same procedures were followed in an examination of the content descriptors assigned to each LGBT-related article. A random $20 \%$ of LGBT-related articles was examined, and interrater reliability at this stage was determined to be $\kappa=.71$.

\section{RESULTS}

The earliest mention of LGBT-related content in the 11 journals is shown in Table 1 and ranges from 1980 to 2012. The first mention was a brief comment in 1980 about the existence of gay art teachers in an Art Education editorial by Edward L. Mattil who served as National Art Education Association president in the 1960s. Mattil was asked what he would do were he in office at present (in 1980), and he replied that he would guard against fragmentation within the organization because "if we developed a men's caucus, singles' caucus, Hispanic caucus, white caucus, gay caucus, Catholic caucus, etc., we soon would be so political and splintered that we would soon fall apart" (Mattil, 1980, p. 26).

From 2000 to 2012, a total of 4,193 articles (full-length articles, research reports, essays, extended abstracts, edited columns, and editorial commentaries) were published in the 11 journals in the study. Of the total number of published articles, 70 (1.67\%) 


\section{Table 1}

Earliest Mention of LGBT-Related Content through 2012

\begin{tabular}{|c|c|c|c|c|c|}
\hline Journal & Year & Issue & Author & Type & Title \\
\hline Art Education & 1980 & $33(3)$ & E. L. Mattil & Positional & Views \\
\hline Arts Education Policy Review & 1992 & $94(1)$ & J. Chanda & Positional & $\begin{array}{l}\text { "Multicultural Education and the } \\
\text { Visual Arts" }\end{array}$ \\
\hline General Music Today & - & - & - & - & - \\
\hline Journal of Dance Education & 2002 & $2(3)$ & D. Risner & Empirical & $\begin{array}{l}\text { "Sexual Orientation and Male } \\
\text { Participation in Dance Education: } \\
\text { Revisiting the Open Secret" }\end{array}$ \\
\hline $\begin{array}{l}\text { Journal of Music Teacher } \\
\text { Education }\end{array}$ & - & - & - & - & - \\
\hline $\begin{array}{l}\text { Journal of Physical Education, } \\
\text { Recreation \& Dance }\end{array}$ & 1992 & $63(4)$ & A. H. Grossman & Positional & $\begin{array}{l}\text { "Inclusion, not } \\
\text { Exclusion: Recreation Service } \\
\text { Delivery to Lesbian, Gay, and } \\
\text { Bisexual Youth" }\end{array}$ \\
\hline $\begin{array}{l}\text { Journal of Research in Music } \\
\text { Education }\end{array}$ & - & - & - & - & - \\
\hline Music Educators Journal & 2005 & $91(3)$ & S. Johnson & Book Review & $\begin{array}{l}\text { Review of Britten, Voice and } \\
\text { Piano: Lectures on the Vocal Music } \\
\text { of Benjamin Britten by G. Johnson }\end{array}$ \\
\hline Studies in Art Education & 1988 & $29(3)$ & D. C. Eaton & Book Review & $\begin{array}{l}\text { Review of The Sexual Perspective: } \\
\text { Homosexuality and Art in the Last } 100 \text { Years } \\
\text { in the West by E. Cooper }\end{array}$ \\
\hline $\begin{array}{l}\text { Update-Applications of } \\
\text { Research in Music Education }\end{array}$ & 2012 & $31(1)$ & M. L. Garrett & Positional & $\begin{array}{l}\text { "The LGBTQ Component of } 21 \text { st-Century } \\
\text { Music Teacher Training: Strategies for } \\
\text { Inclusion from the Research Literature" }\end{array}$ \\
\hline Youth Theatre Journal & 1998 & $12(1)$ & D. Bloom & Empirical & $\begin{array}{l}\text { "Feminist Dramatic Criticism for Theatre } \\
\text { for Young Audiences" }\end{array}$ \\
\hline
\end{tabular}

were determined to contain a significant focus on LGBT-related issues. The distribution of the total number of articles and those with LGBT-related content is presented in Table 2. The highest percentage of LGBT-related articles was represented in Youth Theatre Journal (6.76\%). Four journals did not publish any LGBT-related content during the 13-year period of review: Arts Education Policy Review, General Music Today, Journal of Music Teacher Education, and Journal of Research in Music Education. Though Journal of Physical Education, Recreation \& Dance was determined to contain ten articles related to LGBT issues, none of these specifically addressed dance education. Two journals (Arts Education Policy Review and Journal of Physical Education, Recreation \& Dance) were excluded from the subsequent phase of analysis because they were neither specific to any one of the art disciplines (dance, music, theatre, and visual art) nor did they publish any discipline-specific content related to LGBT issues.

Sixty LGBT-related articles were published in the nine arts discipline-specific journals during the 13 -year period of review $(2.31 \%$ of the total number of articles published). These articles are detailed in Table 3 . With respect to article type, 32 of the 60 $(53.33 \%)$ were positional, $20(33.33 \%)$ were practical, 5 (8.33\%) were empirical, and $3(5.00 \%)$ were historical. The content descriptors assigned to each article were used to 


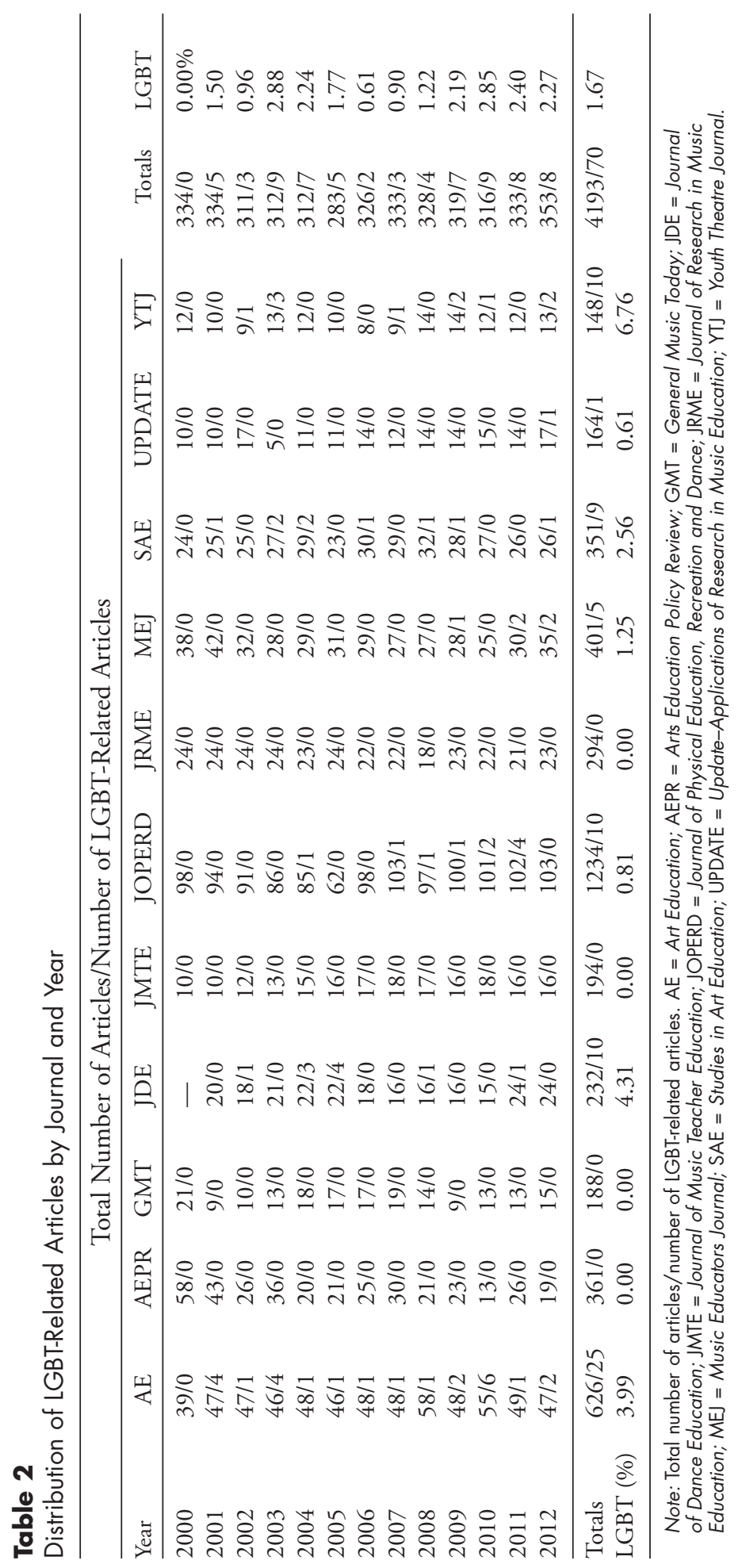


identify the "LGBT-Related Content" referenced in Tables 3 and 4. The most frequent theme concerned pedagogical considerations related to the inclusion of LGBT-related subject matter and its introduction to the classroom $35.00 \%$ of the article subset dealt with pedagogy). Other frequent themes were LGBT contributions to arts disciplines (26.67\%), gender (23.33), social justice (20.00), and homophobia (16.67).

\section{Trends during the 13-Year Period}

The percentage of articles with LGBT-related content was examined for changes in publication rate across the 13-year period of review. Of the total number of articles published each year in the 11 journals, the percentage of LGBT-related articles ranged from a low of $0.00 \%$ in 2000 to a high of $2.88 \%(n=9)$ in 2003 (see Table 1 above). When the percentage of LGBT-related articles was plotted in chronological order by year and the linear relationship was tested, the slope of the line was not statistically significant, $F(1,11)=3.57, p=.08$, suggesting that the percentage of articles with LGBT-related content was steady over time.

The topics identified in the arts discipline-specific journal articles (see Tables 3 and 4) were similarly examined for changes across the 13-year period. The 14 topics with six or more occurrences, each representing $10 \%$ or more of the LGBT-related articles, were similarly plotted in chronological order by year. The linear relationship was tested for each. Of these, only the topic of social justice was shown to have increased in frequency over time such that the slope of the line was statistically significant $F(1,11)=6.72$, $p=.025$. Increases in the topic of social justice roughly paralleled appearances of articles referencing bullying and harassment. Examination of these articles indicates they were influenced by current events, including the 2002 productions of The Matthew Shepard Story and The Laramie Project and, a decade later, national publicity about the harassment-related deaths of several gay students, together with the fatal hazing of drum major Robert Champion at Florida A\&M University.

\section{Content Review of Parallel Journals in Art and Music}

The primary research and practice journals of the National Art Education Association (NAEA) and the National Association for Music Education (NAfME) were additionally analyzed for LGBT-related content since the issue of first publication. These included two research-oriented journals: Studies in Art Education (from 1959) and Journal of Research in Music Education (from 1953), and two practice-oriented journals: Art Education (from 1948) and the Music Educators Journal (and its predecessors from 1914). Published letters to the editor written in response to LGBT-related articles were examined to provide context and to gauge reader reaction. These letters $(n=26)$ appeared in Art Education (letters published between 1994 and 2001) and the Music Educators Journal (letters published in 2010 and 2012). 


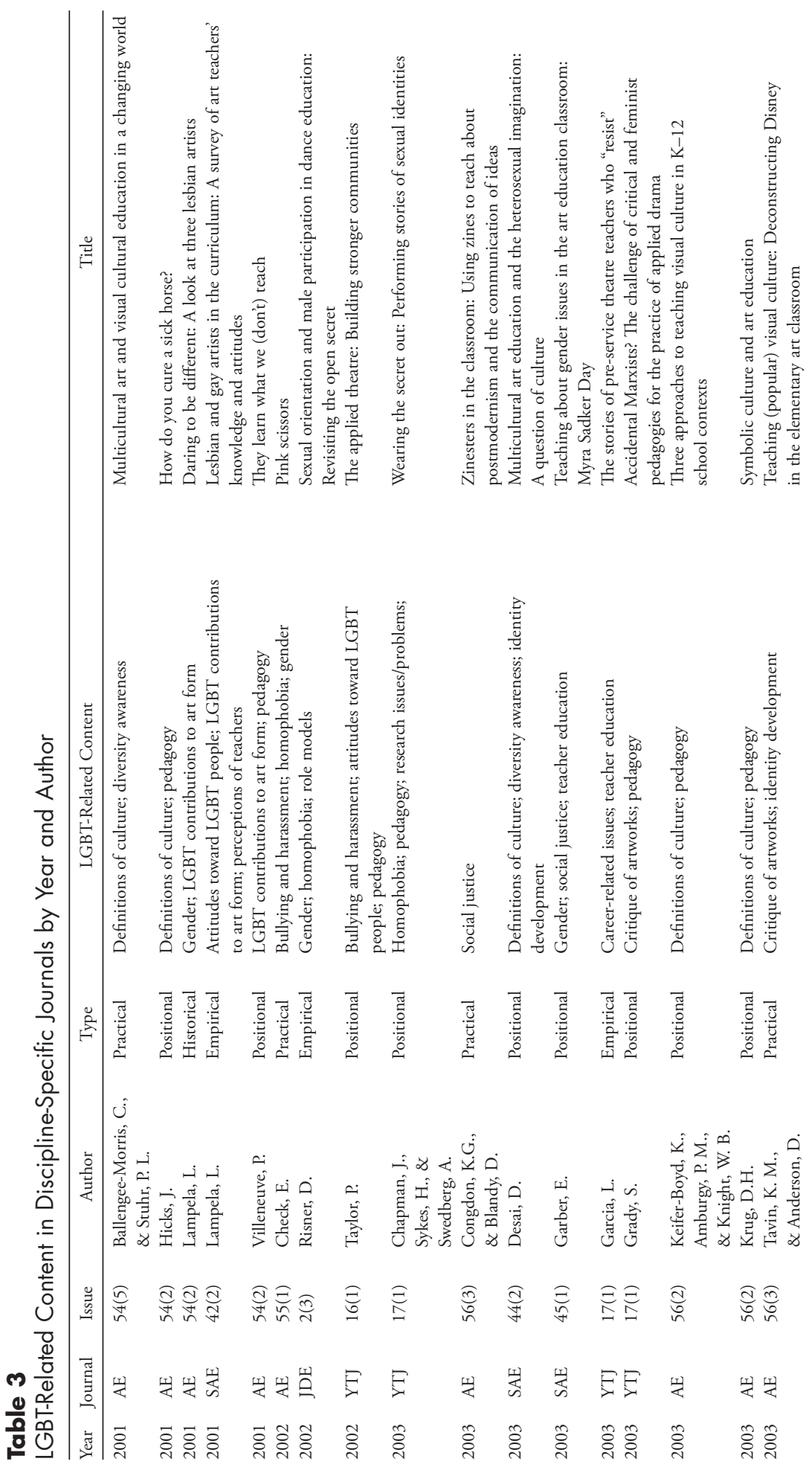




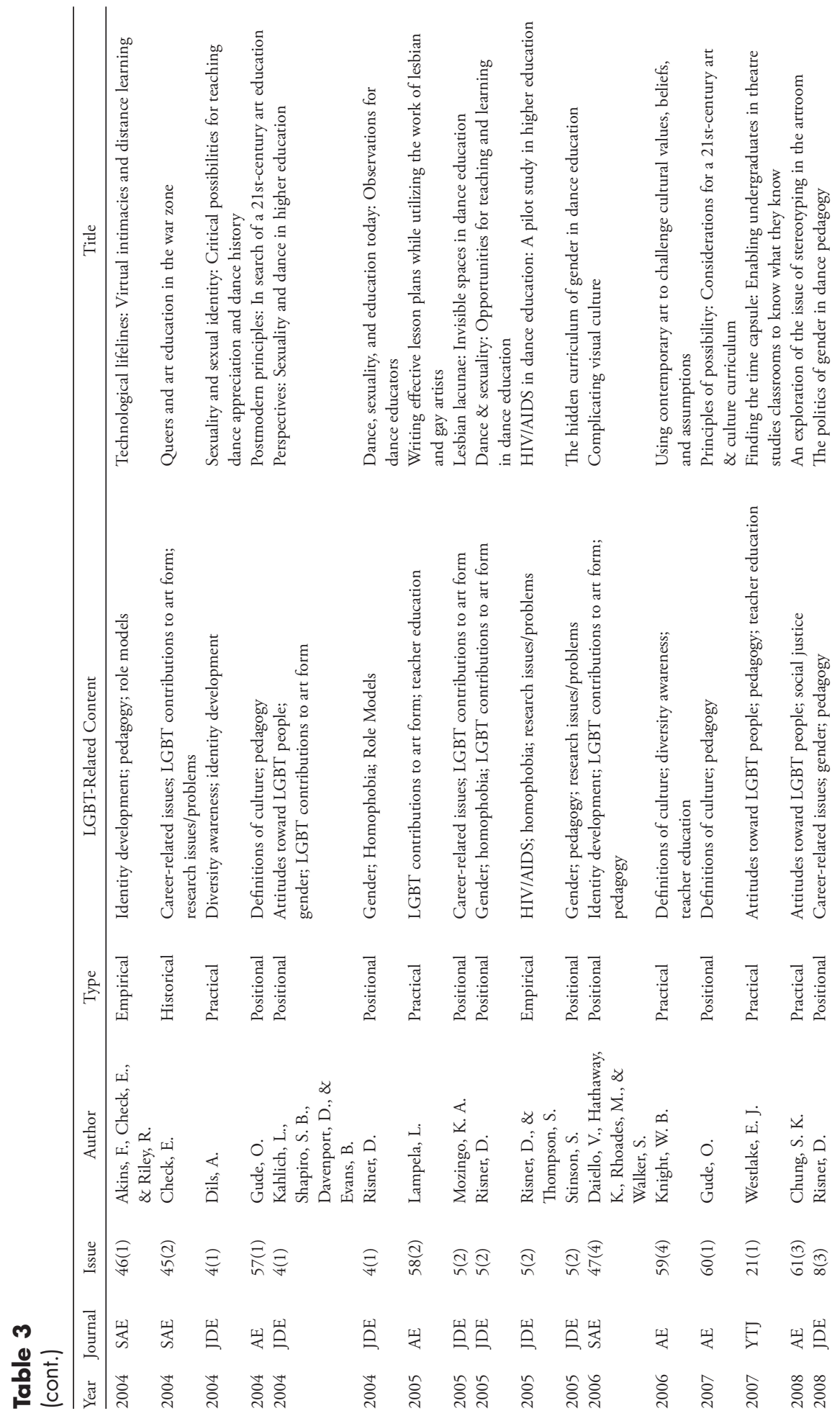




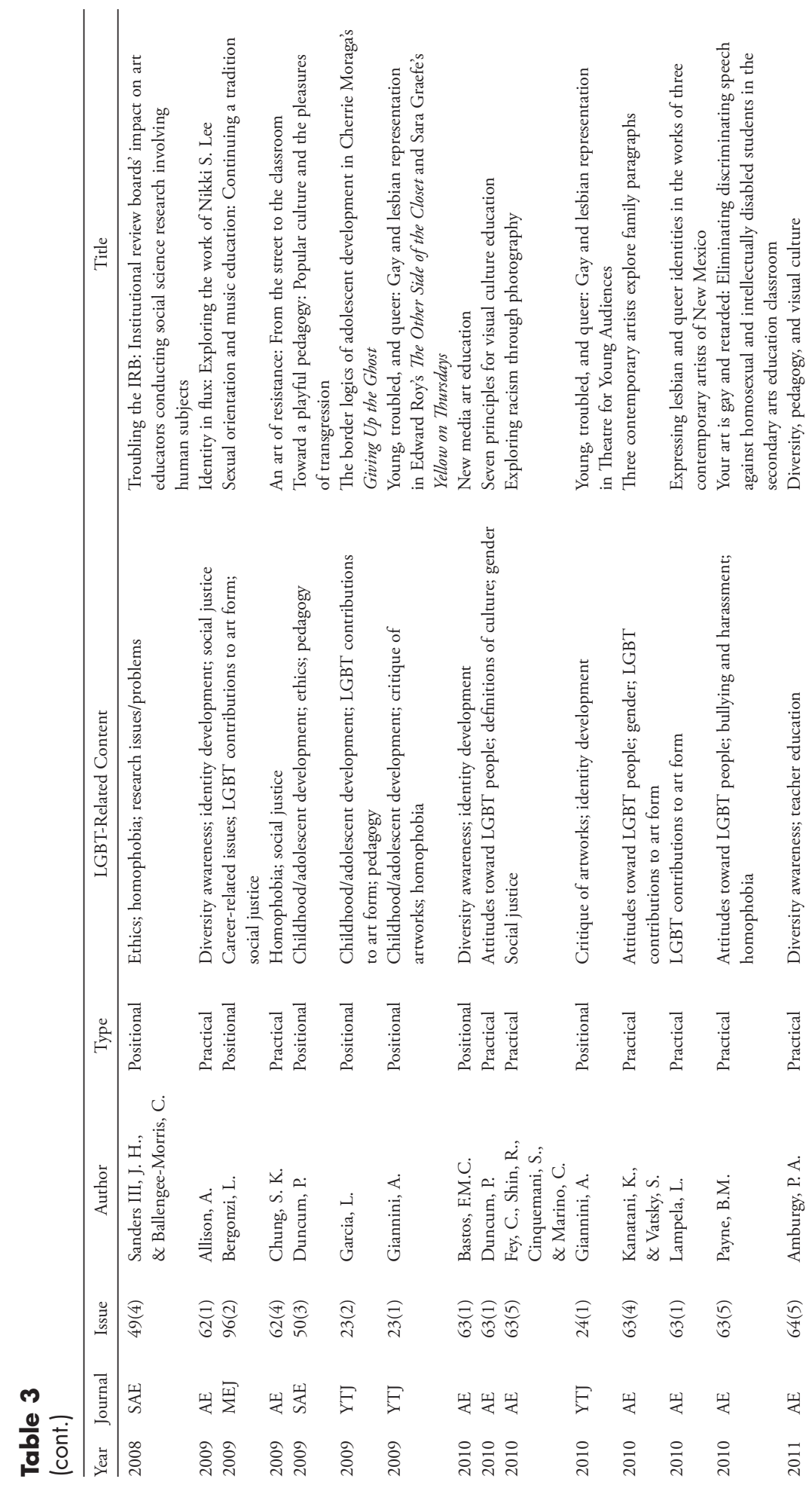




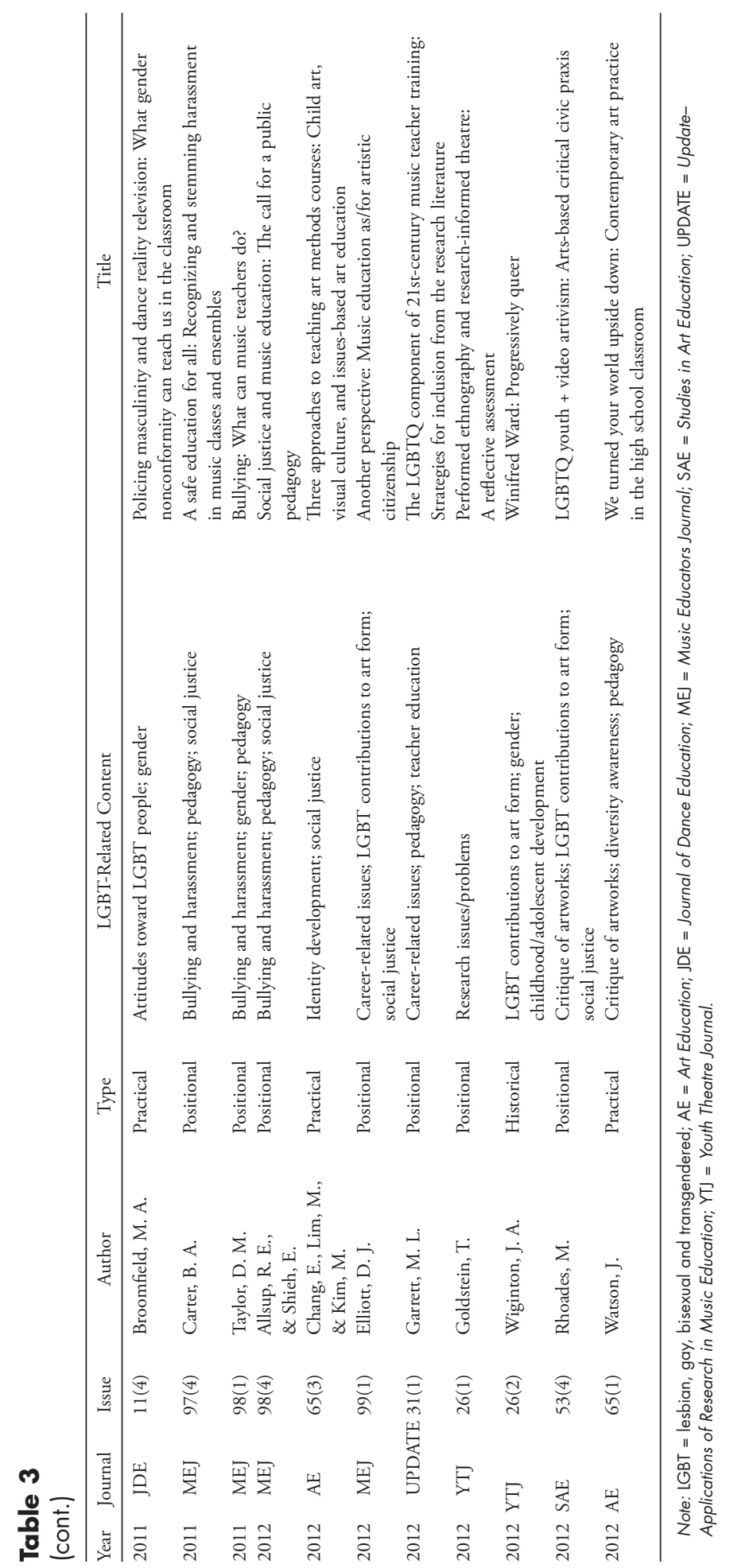




\section{Table 4}

Frequency and Distribution of Content across the 60 LGBT-Related Articles in Discipline-Specific Journals

\begin{tabular}{lcc}
\hline Topic & $f$ & $\%$ \\
\hline Pedagogy & 21 & 35.00 \\
LGBT contributions to art form & 16 & 26.67 \\
Gender & 14 & 23.33 \\
Social justice & 12 & 20.00 \\
Homophobia & 10 & 16.67 \\
Attitudes toward LGBT people & 9 & 15.00 \\
Definitions of culture & 9 & 15.00 \\
Identity development & 9 & 15.00 \\
Diversity awareness & 8 & 13.33 \\
Career-related issues & 7 & 11.67 \\
Teacher education & 7 & 11.67 \\
Bullying and harassment & 6 & 10.00 \\
Critique of artworks & 6 & 10.00 \\
Research issues/problems & 6 & 10.00 \\
Childhood/adolescent development & 4 & 6.67 \\
Role models & 3 & 5.00 \\
Ethics & 2 & 3.33 \\
HIV/AIDS & 1 & 1.67 \\
Perceptions of teachers & 1 & 1.67 \\
\hline
\end{tabular}

Note: Percentages add up to more than $100 \%$ because nearly all articles included multiple topics.

Research-Oriented Journals Beginning in 1994, 14 related articles have been published in Studies in Art Education, not including an earlier book review (Eaton, 1988). As indicated by the subtitle, "a journal of issues and research," Studies in Art Education is purposed more broadly than the Journal of Research in Music Education and contains a range of articles with empirical, research-to-practice, theoretical, and philosophical orientations. There was no published content related to LGBT issues in the Journal of Research in Music Education through 2012. It should be noted that three other journals affiliated with NAfME partially fill parallel roles to those served by Studies in Art Education. These journals were also reviewed for this study (see Table 1 above) and include General Music Today, Journal of Music Teacher Education, and Update: Applications of Research in Music Education.

Articles in Studies in Art Education published since 2000 with LGBT-related content are included in Table 3 (above). Five articles were published prior to 2000. These comprise an editorial (Barrett, 1994) and a qualitative study (Jeffers and Parth, 1996) concerning the role of controversial art in the classrooms of a democratic society, with examples drawn from sexually thematic work by Sally Mann, Robert Mapplethorpe, and others. Two extended essays (Honeychurch, 1995; Lampela, 1995) spoke to the 
inclusion of LGBT artists in art curricula. The fifth article was a philosophic exploration of the impact of AIDS on artistic representations of the human body (Garoian, 1997).

Practice-Oriented Journals Before 1993, Art Education articles addressing LGBTrelated issues were focused on gay and lesbian themes in artworks such as the AIDS Memorial Quilt rather than on LGBT people. In his 1993 article, Edmund Feldman, a former president of the NAEA, spoke directly about a history of art that "is replete with gay and lesbian as well as heterosexual artists" (p. 59). There is no mention of what prompted Feldman toward this topic, but his point was that art educators could easily lose sight of curricular goals if emphasis was placed on the sexual orientation of artists. Feldman wrote that such focus "tends to be a cop-out: it avoids the central task of figuring out what works of art mean, making determinations of their excellence, and deciding how they can bear on the lives of our students" (p. 59). Two gay and lesbian art educators wrote dissenting letters to the editor, prompting Feldman to respond with a terse restatement of his thesis (Check, 1994; Feldman, 1994; Lempala, 1994). This lengthy exchange included mention of a burgeoning caucus of lesbian and gay constituents within the NAEA.

The NAEA's LGB Issues Caucus was profiled in Laurel Lampela's 1996 Art Education article examining traditional attitudes toward homosexuality in society and schools, common concerns of gay and lesbian artists and educators, and the objectives of a new constitution formalizing the caucus. The article also included strategies to address lesbian and gay concerns in the art classroom. Lampela's emphasis on LGBT teachers and artists prompted letters to the editor, including one noting "the depth and degree to which art education is used to promote political and social agendas" (Foley, 1996, p. 5). Another voiced support for teaching the history of fine arts rather than using "my classroom as a platform for gay and lesbian rights" (Gray, 1996, p. 5).

Several Art Education articles in the late 1990s centered on gay and lesbian students, but the next articles to focus on gay and lesbian teachers and artists prompted similar letters to the editor. Each exchange contained wording suggesting differences in the purposes of the university-level authors and the corresponding pre-K-12 writers of letters to the editor. Sensing that the March 2001 articles might be controversial, the editor prefaced with, "Curriculum choices we make embrace certain artists, cultures, ideas, and students while excluding others. Our choices can speak louder than words and leave an unintended legacy. Broadening what we teach can enrich all students" (Villeneuve, 2001, p. 4). One of the two articles profiled three lesbian artists (Lampela, 2001a), to which one letter writer offered, "I think this article needed to be written for the sake of getting something published, therefore fulfilling a requirement to be or stay tenured. I have to wonder if any of our colleagues were offended by the heavy emphasis on their sexual preferences" (Gogolkiewicz, 2001, p. 5), and a second letter writer stated that the author "may be interested more in making a name for themselves in art education than anything else" (Krieger, 2001, p. 5). A third letter writer, a student of the author, was supportive. 
The second of the controversial March 2001 Art Education articles included a diagnosis of public perceptions regarding art education (Hicks, 2001). This prompted one letter writer to comment,

I feel we live in a society of being forced to accept everything . . . oh yes, and having to deal with people who let me know who is gay and who is not.... I was floored when [the author] named gay rights as a recent movement in the field of art education that we could possibly use to change public attitude ... this is one of the roles of art in our schools? (Gogolkiewicsz, 2001, p. 5)

Lampela, author of the article about lesbian artists, responded: "There are and will be lesbian, gay, bisexual, and transgendered students in all of our art classes, and we, as educators, need to understand their struggles for equality in society . . . making LGBT artists more visible is one small way to do this" (2001b, p. 24). In the decade that followed, Lampela and others authored 22 LGBT-related Art Education articles without generating a single letter to the editor. The presentation of LGBT issues in Art Education has become normalized to such extent that at least one related article has been published annually since 2002 without further comment from letter writers.

Analysis reveals a similar progression of LGBT-related content in the Music Educators Journal (MEJ). The MEJs first mention of LGBT issues (Bergonzi, 2009) offered perspectives about the marginalization of LGBT teachers, performers/composers, and students. The article received nationwide attention in online blogs and through social media. The $M E J$ published four full pages of letters to the editor in the March 2010 issue, including an editorial statement that the published letters were representative of the larger number received, though details were not provided. A review of archived correspondence reveals that 77 letters were received in total, of which $46.75 \%$ were supportive and $53.24 \%$ were unsupportive (M. Robinson and E. Wilcox, multiple personal communications concluding on October 10, 2012). The 15 published items included responses by editors and a follow-up letter from the author. The positions expressed in the 12 published reader-submitted letters were weighted toward the supportive view: 7 were supportive (58.33\%), 4 were unsupportive $(33.33 \%)$, and was neutral (8.33\%). One unsupportive author wrote, "How vulgar to include the homosexual agenda boldface in a publication such as MEJ. Does anyone screen these articles for common decency and appropriateness?" (Nickson, 2010, p. 6). Another writer commended the publication: "Great article in the Music Educators Journal. As a (straight) high school choir teacher, I have seen a significant shift in attitudes of students towards their gay peers. Ten years ago, I remember watching gay students struggle to hide their identity to their peers" (Chimenti, 2010, p. 7). Four articles with LGBT-related content have been subsequently published in the pages of the $M E J$ with not a single negative letter to the editor in response. In tandem with Art Education, the presentation of LGBT issues in the Music Educators Journal may have become normalized. 


\section{DISCUSSION}

At $1.67 \%$, the total number of LGBT-related articles in the journals of United Statesbased arts education associations is miniscule. Still, for the period from 2000 to 2012, the percentage of articles in discipline-specific arts education journals $(2.31 \%)$ is comparable to the $2.11 \%$ of LGBT content in counseling journals during the $1990 \mathrm{~s}$ (Phillips et al., 2003). In this study of arts education journals, there was some variation in the percentage of LGBT-related articles from year to year, but the trends of publication rate and presentation of content topics remained steady over time during the 13-year period of review. An exception was the increase in discipline-specific content pertaining to social justice and the parallel, though not statistically significant, publication of content referencing bullying and harassment.

Though these professional arts education associations vary in the number of published journal titles, music education's journals have been the least inclusive of LGBT content measured both by the total number of published articles and by the lack of LGBT content in three of the five journals during the period of review. This study included articles appearing through 2012, and as this manuscript was completed, an LGBT-related article was accepted for publication in a future issue of the Journal of Research in Music Education - the journal's first such article. A discussion of why particular journals have or have not published LGBT-related articles would be speculative given the nature of this study, though a future project might be designed to further detail this situation. A cursory search for LGBT-related article content in other, nonNAfME, English-language music education journals (e.g., Canadian Music Educator; Philosophy of Music Education Review) indicates that such topics are discussed in the broad field of music education, though the most-represented authors (e.g., Elizabeth Gould, Roberta Lamb) have not published on related matters within NAfME journals.

A review of NAfME's Gender and Sexuality SRIG (special research interest group) membership roll suggests that many authors of LGBT-related articles have published in venues other than the association's journals. Some potential reasons relate directly to the missions of the various journals and the typical, perhaps stereotypical, types of articles accepted for publication. In the nine arts discipline-specific journals included in this study, only $8.33 \%$ of articles with LGBT content were based in empirical data. The small number of empirical manuscript submissions, regardless of methodological stance, will continue to constrain LGBT integration within arts education journals, particularly those focused on the presentation of research reports. As Phillips et al. (2003) noted, "It may be unrealistic to hold researchers studying a hidden, oppressed population, that is, LGB people, to the same standard as those who are not doing so with respect to obtaining random, representative samples" (p. 52). This provides a likely opening for the development of rigorous narrative inquiry techniques, building further on the rise of narrative research methodologies in music education (Barrett \& Stauffer, 2009; Clandinin, 2006, 2009). 
The music education journals surveyed here have published a large number of articles where LGBT-related content is mentioned in passing, often in a list of issues pertaining to social justice. These were not included in the present review because there was no specific or sustained focus on the LGBT perspective. The brief mentions, though, outline a potential pathway toward more meaningful integration of LGBT issues within music education's journals. An example can be seen in the Art Education and Studies in Art Education articles of Melody Milbrandt who notes that "most LGBT issues in visual art education are included under the umbrella of social justice concerns" (personal communication, October 15, 2012). Milbrandt began with a research study to identify teachers' desire for the inclusion of socially informed approaches in visual art classrooms (2002). Milbrandt followed the initial study with pedagogical articles exploring intersections between constructivist approaches and socially constructed curricula (e.g., Milbrandt, Felts, Richards, \& Abghari, 2004), further research concerning attitudes toward incorporating issues of social justice (Milbrandt \& Klein, 2008), and a theoretical proposal for the absorption of these topics within a redefinition of creativity (Milbrandt \& Milbrandt, 2011). Milbrandt's articles are focused on broad topics of social justice rather than specific LGBT issues, but they present a potential model for those seeking the integration of LGBT-related research, theory and practice in the pages of NAfME's five journals.

The reliance on positional articles (over $50 \%$ in this analysis) may have served the LGBT arts education community well to this point, but the increased competitiveness for publication will require a deeper, more explicit grounding in theory and philosophy than is evidenced within some of the texts analyzed for this study. Where early Art Education letters to the editor conveyed perceptions that university faculty wrote provocative, opinionated LGBT issues for purposes of tenure or notoriety, the 13-year trend is for positional articles to move from opinion pieces toward the inclusion of rigorous philosophical studies and theoretically grounded scholarship. Additionally, one third of the LGBT-related article content in arts education journals offered pedagogical guidance. A portion of these articles presented teaching materials about LGBT artists and musicians; some offered techniques for teaching about student diversity, inclusion, and antiharassment measures; while others proposed ways that the arts education professions might provide support for LGBT teachers.

One frequently employed strategy when approaching complex or difficult issues is for journal editors to gather related articles in a special focus issue. Single-topic journal issues like these provide opportunities for editors to craft a presentation of perspectives that collectively exhibit desired characteristics of content, balance, comprehensiveness and style. For example, the Journal of Dance Education published two special focus issues on sexuality in 2004 and 2005 (vol. 4, no. 1 and vol. 5, no. 2). Where such special issues might not be practical for political reasons, editors of journals affiliated with professional associations might choose to encourage all authors to recognize LGBT concerns whenever relevant to article content. 
The letters generated by controversial LGBT-oriented articles suggest that one problem of addressing LGBT issues is the number of potential focus populations. Teachers can be gay, artists and musicians can be lesbian, and students may come from single-sex or other nontraditional family structures. Some students will be LGBT, but many are too young to have a firm sense of their sexual identities. This study's analysis of letters to the editor is not intended to suggest that controversy is to be avoided, but to identify where controversy is likely to arise-particularly if the controversy itself could jeopardize reception of the author's primary thesis. These findings suggest that authors of LGBT-related studies and manuscripts must clearly state the parameters of their work, since LGBT-focused content in pre-K-12 educational settings will likely center on one subset of the population rather than apply equally to all. Writers may avoid points of controversy by recognizing these and other withingroup differences while writing with clarity and coherence for the majority of readers who are heterosexual.

Finally, this study's analysis of letters to the editor in Art Education and the Music Educators Journal revealed three points of interest for those seeking strategies for the inclusion of LGBT-related content in these and other journals where little or no such content exists. First, reader response suggests that LGBT-related article content has been uncontroversial when associated with students and/or current events. Teachers manage curricular content, students, and changing situations on a daily basis, and situating LGBT discussions within this framework-relating the familiar to the less familiarmay facilitate a reader's willingness to consider new viewpoints. Second, controversy has followed the initial publication of articles featuring LGBT-related content associated with adults, whether teachers or artists/musicians. Authors or editors may wish to strategically consider the optimal publication venues for LGBT-related articles focused on teachers and adult artists/musicians, perhaps pairing them with articles focused on students or current events. Third, as indicated by published identification information, university-level instructors authored each controversial article, while pre-K-12 arts educators contributed all published, unsupportive response letters. Editors and researchers might consider the development of articles and studies coauthored by university faculty and pre-K-12 teachers such as the recent Music Educators Journal article by Randall Allsup and Erik Shieh (2012).

This study examined the state of LGBT content in the pages of journals supported by the major professional arts education associations in the United States. One response to the small number of related articles might be to turn attention toward other, independent journals wherein LGBT-related content appears more frequently. However, journals affiliated with professional educational associations must reflect the organization's membership of teachers, at all levels and types of institutions, and the students they serve. These audiences are broad, diverse, and include LGBT individuals with concerns that have rarely been voiced in our journals. This analysis suggests the silence may be ending. 


\section{AUTHOR NOTE}

Portions of this paper were presented at the 2nd Symposium on LGBT Studies and Music Education (University of Illinois at Urbana-Champaign) on October 19, 2012.

\section{REFERENCES}

Allsup, R. E., \& Shieh, E. (2012). Social justice and music education: The call for a public pedagogy. Music Educators Journal, 98(4), 47-51.

Barrett, M. S., \& S. L. Stauffer (Eds.). (2009). Narrative inquiry in music education: Troubling certainty. Dordrecht, Netherlands: Springer.

Barrett, T. (1994). Editorial: Culture wars. Studies in Art Education, 36(1), 3-6.

Bergonzi, L. (2009). Sexual orientation and music education: Continuing a tradition. Music Educators Journal, 96(2), 21-25. doi: 10.1177/0027432109350929

Blumer, M. L. C., Green, M. S., Knowles, S. J., \& Williams, A. (2012). Shedding light on thirteen years of darkness: Content analysis of articles pertaining to transgender issues in marriage/ couple and family therapy journals. Journal of Marital and Family Therapy, 38(s1), 244-256. doi: 10.1111/j.1752-0606.2012.00317.x

Buhrke, R. A., Ben-Ezra, L. A., Hurley, M. E., \& Ruprechet, L. J. (1992). Content analysis and methodological critique of articles concerning lesbian and gay male issues in counseling journals. Journal of Counseling Psychology, 39(1), 91-99.

Check, E. (1994). Letter to the editor. Art Education, 47(2), 6-7.

Chimenti, S. (2010). Letter to the editor. Music Educators Journal, 96(3), 7. doi: $10.1177 / 0027432110361699$

Clandinin, D. J. (Ed.). (2006). Handbook of narrative inquiry: Mapping a methodology. Thousand Oaks, CA: Sage.

Clandinin, D. J. (2009). Troubling certainty: Narrative possibilities for music education. In M. S. Barrett \& S. L. Stauffer (Eds.), Narrative inquiry in music education: Troubling certainty (pp. 201-209). Dordrecht, Netherlands: Springer.

Clark, W. M., \& Serovich, J. M. (1997). Twenty years and still in the dark? Content analysis of articles pertaining to gay, lesbian, and bisexual issues in marriage and family therapy journals. Journal of Marital and Family Therapy, 23(3), 239-253.

Eaton, D. C. (1988). The sexual perspective: Homosexuality and art in the last 100 years in the West, by E. Cooper [Book Review]. Studies in Art Education, 29(3), 315-318.

Feldman, E. B. (1993). Best advice and counsel to art teachers. Art Education, 46(5), 58-59.

Feldman, E. B. (1994). Letter to the editor. Art Education, 47(2), 8.

Foley, P. (1996). Letter to the editor. Art Education, 49(5), 5.

Garoian, C. R. (1997). Art education and the aesthetics of health in the age of AIDS. Studies in Art Education, 39(1), 6-23.

Gogolkiewicz, M. (2001). Letter to the editor. Art Education, 54(5), 5.

Gray, L. (1996). Letter to the editor. Art Education, 49(5), 5.

Hicks, J. (2001). How do you cure a sick horse? Art Education, 54(2), 6-10.

Honeychurch, K. G. (1995). Extending the dialogues of diversity: Sexual subjectivities and education in the visual arts. Studies in Art Education, 36(4), 210-217.

Huang, Y., Brewster, M. E., Moradi, B., Goodman, M. B., Wiseman, M. C., \& Martin, A. (2010). Content analysis of literature about LGB people of color: 1998-2007. The Counseling Psychologist, 38(3), 363-396. doi: 10.1177/0011000009335255 
Jeffers, C. S., and Parth, P. (1996). Relating controversial contemporary art and school art: A problem-position. Studies in Art Education, 38(1), 21-33.

Jennings, T., \& Macgillivray, I. K. (2011). A content analysis of lesbian, gay, bisexual, and transgender topics in multicultural education textbooks. Teaching Education, 22(1), 39-62. doi: $10.1080 / 10476210.2010 .538474$

Krieger, P. (2001). Letter to the editor. Art Education, 54(5), 5.

Lampela, L. (1995). A challenge for art education: Including lesbians and gays. Studies in Art Education, 36(4), 242-248.

Lampela, L. (1996). Concerns of gay and lesbian caucuses within art, education, and art education. Art Education, 49(2), 20-24.

Lampela, L. (2001a). Daring to be different: A look at three lesbian artists. Art Education, 54(2), $45-51$.

Lampela, L. (2001b). Letter to the editor. Art Education, 54(5), 24.

Mattil, E. L. (1980). Views. Art Education, 33(3), 26.

Milbrandt, M. K. (2002). Addressing contemporary social issues in art education: A survey of public school art educators in Georgia. Studies in Art Education, 43(2), 141-157.

Milbrandt, M. K., Felts, J., Richards, B., \& Abghari, N. (2004). Teaching-to-learn: A constructivist approach to shared responsibility. Art Education, 57(5), 19-24, 33.

Milbrandt, M. K., \& Klein, S. R. (2008). Survey of art teacher educators: Qualifications, identity, and practice. Studies in Art Education, 49(4), 343-357.

Milbrandt, M. K., \& Milbrandt, L. (2011). Creativity: What are we talking about? Art Education, $64(1), 8-13$.

Nickson, D. (2010). Letter to the editor. Music Educators Journal, 96(4), 6. doi: $10.1177 / 0027432110361699$

Phillips, J. C. (2010). Eight articles, eight journals, eight years: Selected disappointments and celebrations from an outstanding major contribution. The Counseling Psychologist, 38(3), 434-441. doi: $10.1177 / 0011000009346324$

Phillips, J. C., Ingram, K. M., Smith, N. G., \& Mindes, E. J. (2003). Methodological and content review of lesbian-, gay-, and bisexual-related articles in counseling journals: 1990-1999. The Counseling Psychologist, 31(1), 25-62. doi: 10.1177/0011000002239398

Van Voorhees, R., \& Wagner, M. (2002). Among the missing: Content on lesbian and gay people in social work journals. Social Work, 47(4), 345-354.

Villeneuve, P. (2001). They learn what we [don't] teach. Art Education, 54(2), 4.

Young, A., \& Middleton, M. J. (2002). The gay ghetto in the geography of education textbooks. In R. M. Kissen (Ed.), Getting ready for Benjamin: Preparing teachers for sexual diversity in the classroom (pp. 91-102). Lanham, MD: Rowman \& Littlefield. 